\title{
RECURSOS, DECISÃO E PODER Conselhos gestores de políticas públicas de Curitiba
}

\author{
Mario Fuks \\ Renato Perissinotto
}

\section{Introdução}

Os estudos sobre os fenômenos políticos apresentam com muita freqüência, implícita ou explicitamente, uma questão que não hesitaríamos em qualificar de "universal", a saber, a questão do poder. Quando se discute uma política pública, o funcionamento de uma determinada instituição ou os diversos sentidos da "democracia”, de uma forma ou de outra, o objetivo é quase sempre saber "quem tem o poder".

A questão, no entanto, é tão fácil de ser formulada quanto difícil de ser respondida. Ainda que possamos encontrar um relativo consenso acerca da definição mais genérica de poder - isto é, como uma relação de conflito e de predomínio -, as dificuldades metodológicas para se responder à

Artigo recebido em janeiro/2005

Aprovado em outubro/2005 questão universal (quem tem poder?) são tão grandes e os limites das respostas dadas tão discutidos que aquele consenso acaba por ter pouco significado operacional.

As duas respostas mais usuais a essa questão são oriundas da tradição weberiana. Ambas entendem o poder como sinônimo de capacidade de influenciar o processo decisório, isto é, de impor aos outros um determinado curso de ação em relação a um assunto específico (Wright Mills, 1985, p. 65; Kaplan e Lasswell, 1998, p. 110; Dahl, 1970, 1989). A origem comum na tradição weberiana não impediu, entretanto, que essas duas perspectivas produzissem orientações metodológicas bastante distintas, que acabaram por se consagrar na literatura como o "método posicional" e o "método decisional".

O método posicional pode ser encontrado numa infinidade de textos, entre os quais o mais famoso é certamente A elite do poder, de C. Wright Mills. Neste livro, Mills afirma que o poder 
de tomar as decisões políticas encontra-se nas mãos daqueles indivíduos que ocupam as posições institucionais estratégicas numa comunidade. Sendo assim, o procedimento para saber quem governa a comunidade em análise consistiria, primeiro, em identificar essas posições estratégicas de mando e, em seguida, fazer aquilo que Mills chama de "sociologia das posições institucionais" (1985, p. 63).

Os defensores do chamado método decisional, no entanto, identificaram uma falha metodológica fundamental no procedimento analítico de Wright Mills, a saber, a inadequação entre a sua definição conceitual de poder e o método por ele utilizado para operacionalizar aquele conceito. Se o poder é a expressão da capacidade de impor aos outros, numa relação social, um determinado curso de ação, então o seu estudo não pode se limitar a identificar os recursos possuídos por atores políticos e derivar mecanicamente da quantidade e importância desses recursos o poder de seus proprietários. Enfim, se o poder é o poder de decidir, somente o estudo de alguns processos decisórios concretos revelaria ao analista os indivíduos ou grupos sociais capazes de exercer o poder (Dahl, 1970, 1989; Polsby, 1963). Segundo essa perspectiva, exerceria o poder aquele indivíduo ou grupo que, num processo decisório específico e conflituoso, conseguisse fazer com que as suas preferências prevalecessem sobre as preferências dos demais.

Apesar de bastante persuasiva, essa postura metodológica não escapou de críticas também contundentes, desenvolvidas em duas direções.

Primeiramente, alguns autores (Bachrach e Baratz, 1969a e b; Crenson, 1971) observaram que a análise de processos decisórios, tal como feita por Dahl, era insuficiente para identificar os "poderosos" de uma comunidade, e isso por duas razões. Primeira, aqueles que participam diretamente do processo decisório podem decidir levando em conta os interesses de grupos exteriores a este processo, comportando-se por meio daquilo que a literatura chamou de "regra das reações antecipadas". Nesses casos, temendo as sanções que sofreriam se afetassem negativamente os interesses do grupo em questão, os decisores antecipar-se-iam a qualquer ordem expressa, evitariam qualquer tipo de resistência frontal e, por fim, acabariam adotando o comportamento desejado pelos "verdadeiros poderosos". Segunda, o processo decisório seria apenas o resultado visível de um processo social e político anterior que consistiria na mobilização consciente por grupos dominantes de uma série de mitos e valores e mesmo de recursos de força que, pela estigmatização, desqualificação ou simples repressão, excluiriam da agenda pública uma série de "queixas", reduzindo o processo decisório a um conjunto de "temas seguros". Feita nesses termos, essa crítica não representou nenhum rompimento epistemológico com o "método decisional", já que o poder continua a ser entendido como uma relação de conflito observável (ainda que às vezes mais difícil de ser visualizado em função da regra das reações antecipadas ou da exclusão política) entre agentes conscientes de seus interesses e agindo, basicamente, de maneira estratégica (Lukes, 1976; Foucault, 1995; Bourdieu, 1989).

Ao contrário, o segundo tipo de crítica feita ao método decisional representou um rompimento epistemológico (declarado ou não) com a tradição weberiana (e, portanto, com todas as vertentes vistas anteriormente), já que, na análise do poder, seus autores preferiram adotar uma perspectiva que poderíamos chamar de "estruturalista". Apesar das grandes diferenças teóricas e metodológicas, os autores filiados a esse campo analítico abandonaram, todos eles, a proposta de reduzir o fenômeno do poder a uma interação entre agentes conscientes de suas preferências subjetivas. O poder passou a ser visto como um conjunto de relações sociais institucionalizadas, isto é, capazes de se interiorizarem nos valores e nas percepções dos atores sociais que, assim, por meio de suas práticas, reproduziriam relações essencialmente hierárquicas, produtoras de uma distribuição desigual e regular de recursos de natureza diversa (econômico, político, simbólico, cultural etc.). Na perspectiva dos autores filiados a esse campo teórico, não se trata de negar a existência de ações estratégicas e conscientes por parte do atores sociais, mas sim de afirmar que tais ações são a parte visível de uma dimensão inconsciente da ação social, isto é, aquela produzida por longos processos de socialização a que os indivíduos estão submetidos e que definem para eles a razoabilidade de determinados objeti- 
vos a serem perseguidos. Como parece claro, a operacionalização metodológica dessa visão do poder é muito mais complicada do que a análise de conflitos observáveis no processo decisório. Segundo essa perspectiva, somente a recuperação histórica do longo processo que nos conduziu ao estado atual das relações sociais pode mostrar que esse "estado" está longe de expressar um consenso genuíno entre os agentes sociais, mas se constitui, na verdade, na cristalização final (e não desejada por ninguém) de lutas, vitórias e derrotas pretéritas.

O presente artigo analisa os conselhos gestores de políticas públicas da cidade de Curitiba, ${ }^{1}$ tendo como premissa a questão supracitada sobre o poder no contexto dessas instituições participativas. Neste caso, a questão torna-se ainda mais relevante, tendo em vista a intenção declarada (no plano da legislação) de que essas instituições sirvam para ampliar a participação popular e, assim, melhorar a qualidade da democracia brasileira. Ora, a ampliação dessa participação só produziria o efeito que dela se espera caso os novos participantes sejam capazes de exercer o poder em seu interior, seja interferindo no processo decisório, seja moldando a agenda pública. Propomos, nesse sentido, dois eixos temáticos interligados: de um lado, pretendemos discutir questões teóricas e metodológicas relativas ao conceito de poder e, de outro, procuramos fazê-lo de forma, por assim dizer, "aplicada", tentando identificar o modelo analítico mais apropriado para o estudo das relações de poder no interior de instituições marcadas por uma participação ampliada e por um baixo grau de institucionalização dos seus procedimentos internos, tais como os conselhos gestores de políticas públicas.

A pesquisa fez uso das duas primeiras perspectivas resumidas acima, quais sejam, a do método posicional e a do método decisional. Fizemos isso lançando mão de dois instrumentos de coleta de dados. De um lado, por meio da aplicação de um questionário, procuramos identificar os recursos organizacionais e materiais dos participantes dos conselhos analisados, assim como os aspectos motivacionais de sua conduta política; de outro lado, procuramos fazer uma análise do processo decisório em si, visando a identificar os atores que, dentro dos conselhos, se destacaram na condução desse processo. Conjugando esses dois procedimentos analíticos, a nossa intenção era ver se seria possível identificar a existência de alguma relação regular entre a posse de determinados recursos e a capacidade de influenciar o processo decisório.

Ainda que esse procedimento tenha nos propiciado descobertas interessantes, o fato é que vários dos limites apontados pelos seus críticos se manifestaram ao longo da análise. Chegamos à conclusão de que a identificação das relações de poder num determinado contexto só pode ser completa se conjugarmos uma série de variáveis qualitativamente distintas, mas francamente complementares. Neste artigo, não é nosso interesse produzir antinomias, mas defender a idéia de que, entre as posturas teóricas supracitadas, há mais uma relação de complementariedade (certamente hierarquizada) do que de mera oposição.

$\mathrm{O}$ trabalho está dividido em três partes. $\mathrm{Na}$ primeira, apresentamos uma análise panorâmica do processo decisório nos diversos conselhos analisados. Pretendemos identificar os atores que exercem maior influência no processo de tomada decisão dentro dessas instituições. Em seguida, apresentamos um estudo dos conselhos gestores a partir dos recursos. O objetivo, reiterando, é identificar os recursos materiais, institucionais e subjetivos mobilizados pelos conselheiros. Fazemos isso com base na crença de que se é verdade que a "influência política" não pode ser diretamente derivada da posse de recursos, a desigualdade de recursos entre os agentes pode ser um elemento central, ao menos em alguns casos, para entender a desigualdade política. Por fim, na terceira parte, reconhecemos que os procedimentos analíticos por nós adotados revelam vários aspectos interessantes dos conselhos gestores, mas, ao mesmo tempo, mantêm na sombra uma série de elementos que nos parecem fundamentais para captar de forma plena as relações de poder que se cristalizam nessas instituições. Nesse sentido, pretendemos nessa terceira parte apresentar alguns desses elementos. No entanto, é preciso fazer aqui duas observações. Primeiramente, os "dados" apresentados na terceira seção não fazem parte dos objetivos inicialmente fixados pela pesquisa; não foram, portanto, sistematicamente coletados. Em segundo lugar, pela sua própria natureza (infor- 
mações de caráter histórico ou coletadas por meio de observação direta de reuniões e conferências), não se prestam ao tratamento quantitativo que buscamos imprimir à maior parte de nossas das análises. É preciso, portanto, que essas explicações adicionais sejam vistas como "prováveis" e que as informações apresentadas sejam lidas como "indícios".

\section{Poder e decisão ${ }^{2}$}

A análise a respeito da influência dos grupos no interior dos conselhos $^{3}$ focaliza quatro momentos do processo deliberativo, a saber: 1) apresentação inicial de um determinado tema para a apreciação da plenária (quem introduz o assunto, iniciando o debate); 2) estabelecimento da interlocução (quem institui o debate); 3) encaminhamento de proposta sobre o tema em questão para a deliberação (quem encaminha a proposta); e, por fim, 4) qual o resultado dessa deliberação (aprovação ou não).

Entre os conselhos gestores de políticas sociais em Curitiba, identificamos, ao menos, um ponto de convergência: há um claro predomínio dos gestores em todos os momentos do processo decisório. A esse respeito, o Conselho Municipal de Saúde de Curitiba (CMSC) é o que apresenta a mais bem equilibrada distribuição de iniciativa política. Ainda assim, pode-se facilmente perceber que, embora em minoria, ${ }^{4}$ os atores governamentais controlam a iniciativa do debate neste conselho. Isso ocorre, em parte, devido ao papel central que o gestor tem ocupado na mesa diretora, na permanente condição de presidente do conselho, abrindo, freqüentemente, o debate referente aos assuntos em pauta nas reuniões. Isso também revela o peso do conhecimento técnico na dinâmica da instituição, que confere aos assessores técnicos um papel decisivo na disseminação da informação a respeito das ações e dos programas governamentais, assim como dos aspectos técnicos envolvidos em assuntos específicos de interesse do conselho.

Se comparado com os demais conselhos estudados, o Conselho Municipal de Saúde de Curitiba pode ser considerado não apenas uma arena de debate, mas de controvérsia pública. Praticamente, a metade ( $46 \%$ dos casos) dos assuntos da agenda do conselho gerou debate e, aproximadamente, um em cada dez assuntos em pauta (12,8\%) suscitou contestação, ${ }^{5}$ tal como definida por nossa metodologia.

Sendo o usuário o segmento da sociedade civil que mais atua no momento do debate e que mais gera controvérsia, identificamos a seguinte dinâmica na reunião do conselho: 1) fazendo uso de recursos cognitivos e das prerrogativas dos cargos que ocupam, os atores estatais lideram as discussões, apresentando os assuntos da pauta, esclarecendo questões de ordem técnica, divulgando informações governamentais, enfim, abrindo $\mathrm{O}$ debate; 2) os usuários apresentam-se como interlocutores e, em certas circunstâncias, contrapõem (apoiados pelos trabalhadores) seus argumentos aos dos gestores. Portanto, o usuário e o gestor são segmentos ativos não apenas no sentido de participarem do debate, mas também porque lhe conferem a qualidade de confrontação de idéias.

Ainda no caso do CMSC, o gestor encaminhou para a votação quase o mesmo número de propostas (108) que os demais segmentos que têm assento no conselho juntos (129). Embora esse número não seja tão expressivo quanto o da iniciativa no campo do debate, ele consolida a liderança do gestor no processo decisório do conselho. Da mesma forma, os dados referentes ao encaminhamento de propostas deixam claro que o usuário é o segmento da sociedade civil organizada mais ativo nas reuniões. Já os prestadores de serviço mantêm-se praticamente invisíveis durante todo o processo, tanto no debate como no encaminhamento de propostas para deliberação.

Quando consideramos apenas as deliberações em que houve controvérsia, seguidas de encaminhamento de mais de uma proposta para votação, o gestor permanece sendo o segmento com maior iniciativa no encaminhamento da proposta original para votação (21 propostas), seguido pelo usuário (16 propostas). Nesse contexto, o trabalhador torna-se mais ativo, aproximando-se do usuário (14 propostas). Por sua vez, o usuário destaca-se na qualidade de formulador de propostas alternativas (19 propostas), superando o gestor (11 propostas). Considerando a totalidade das propostas encaminhadas em contexto de controvérsia, o usuário (35 propostas) supera o gestor (32 propostas). Percebe-se, então, que o con- 
flito político no âmbito deste conselho gera um cenário de equilíbrio, tendo como novidade uma maior presença do trabalhador e o papel contestador do usuário. Considerando, ainda, que o usuário apresentou um número ligeiramente superior (11) de propostas de resolução ao CMSC do que o gestor (9), a idéia que há um relativo equilíbrio de influência política no interior dessa arena fica reforçada.

O que, no entanto, nos impede de realizar uma avaliação conclusiva a respeito da influência de cada segmento no processo decisório do CMSC é o fato de que praticamente todas as propostas encaminhadas foram aprovadas. Vale perguntar, portanto, por que o conselho teria como regra aprovar as propostas apreciadas em suas reuniões. Podemos, aqui, apenas especular, supondo, por exemplo, que ele tende a estruturar sua agenda com temas e propostas que estejam em sintonia com os interesses da maioria de seus membros, excluindo temas não consensuais. Podemos igualmente supor que determinados setores consigam "impor", na agenda do conselho, os temas que atendem apenas aos seus próprios interesses. Em ambos os casos, a influência é exercida no processo de constituição de um "filtro", o qual define quais as questões estarão presentes e quais serão excluídas do processo decisório (Cobb e Ross, 1997). Sem o exame do processo de formação da agenda, não é possível avaliar se e em que medida os interesses de cada segmento foram atendidos mediante a inclusão e a exclusão de determinados assuntos na pauta de deliberação do conselho.

A análise do processo decisório nesse conselho indica, portanto, que a explicação baseada exclusivamente nos dados fornecidos pela observação da própria deliberação é insuficiente para entendermos os procedimentos por meio dos quais a influência política é exercida. Essa questão nos ocupará a partir da próxima seção, na qual apresentaremos fatores externos ao funcionamento do conselho que, a nosso ver, podem afetar a distribuição da participação e da influência política no interior da instituição.

No caso do Conselho Municipal de Assistência Social de Curitiba (CMASC), o predomínio do setor governamental tende ao monopólio da iniciativa política. Este setor, por meio da
Fundação de Assistência Social (FAS) e de outras secretarias municipais presentes neste conselho, é responsável pelo encaminhamento de $75,6 \%$ das propostas para deliberação (das 37 deliberações em que foi possível identificar o ator), enquanto o setor não-governamental, com predomínio dos prestadores, é responsável por apenas $24,4 \%$ das deliberações. Além disso, o controle dos gestores é, nesse caso, exercido sem que qualquer contestação ou, ao menos, debate seja suscitado. Pouquíssimas vezes as intervenções iniciais sobre um determinado assunto dentro do conselho foram seguidas por debate. Encontramos apenas dois casos em que um ator estabeleceu o debate a partir da intervenção daquele que introduziu um determinado tema. Nesses casos, a intervenção do segundo ator não teve qualquer sentido de contestação da fala do ator inicial. Ou seja, a contestação é absolutamente ausente dessa instituição durante a gestão analisada.

Se seguirmos uma indicação da abordagem decisional, essa preponderância avassaladora dos atores governamentais não deve ser interpretada como exercício de relação de poder. Isso porque, de acordo com essa perspectiva, só há relação de poder onde houver um conflito aberto e observável entre duas preferências antagônicas. Seguindo esse raciocínio, poderíamos, então, dizer que no processo decisório do CMASC não há relações de poder. O predomínio do gestor seria menos relevante do que o consenso que perpassa o processo decisório nesta instituição e que expressaria, na verdade, uma concordância entre os diversos participantes em torno dos principais temas ali discutidos. Assim, onde há consenso não há poder. No entanto, conforme veremos na próxima seção, uma análise que se limite a observar o processo decisório do CMASC não permite ver que o consenso que ali predomina expressa, de fato, as relações de poder exercidas externa e anteriormente ao processo decisório investigado. Isso indica que o pressuposto teórico da abordagem decisional, segundo o qual as relações de poder só se revelam no âmbito de processos decisórios concretos e conflituosos, é incapaz de explicar todas as dimensões que constituem aquelas relações. Conseqüentemente, o desdobramento metodológico desse pressuposto - de que o analista deve observar algumas decisões concretas e procurar 
identificar aqueles que conseguem aprovar e/ou vetar propostas, mesmo contra a oposição dos outros - é, no mínimo, incompleto.

\section{Recursos e influência política}

Como vimos na introdução, a explicação da influência política a partir da posse de recursos afirma que a capacidade de cada ator para atingir seus objetivos políticos está direta e proporcionalmente associada aos recursos que ele dispõe, recursos que, por sua vez, são atributos das posições sociais e institucionais em que se encontram. Nesta seção, discutiremos a capacidade explicativa desse modelo em relação ao Conselho Municipal de Assistência Social de Curitiba e ao Conselho Municipal de Saúde de Curitiba. A análise dos recursos é importante por duas razões. Primeiramente, porque os recursos, sobretudo os de natureza institucional, permitem explicar o predomínio dos gestores na "condução" do processo decisório. Em segundo lugar, e mais importante, ela abre caminho para a análise dos constrangimentos estruturais que definem a distribuição, sempre desigual, dos diversos recursos (materiais, organizacionais, institucionais, simbólicos, políticos) que os atores mobilizarão a fim de implementar suas estratégias dentro dos conselhos.

Como observação preliminar, podemos dizer que, se é verdade que nos conselhos analisados há desigualdades na distribuição de recursos, essas desigualdades são dispersas e não cumulativas (Fuks, Perissinotto e Ribeiro, 2003): o fato de um segmento ter mais de um recurso não significa que ele tenha mais de todos os outros recursos. ${ }^{6}$ Cabe, portanto, a questão: como relacionar tal dispersão de recursos com o monótono predomínio dos gestores na condução do processo decisório dentro do CMASC? Ou, situando a questão teórica que serve de fio condutor para esta discussão, qual a relação entre recursos e influência no processo decisório neste caso específico?

A princípio, a distribuição de recursos (de renda, de escolaridade, organizacionais, de ativismo) poderia sugerir que a desigualdade não é um atributo característico do CMASC. De fato, ainda que os recursos de renda e escolaridade sejam mais concentrados, cabendo ao segmento dos gestores uma posição superior e aos usuários o posto mais baixo, os outros tipos de recursos são distribuídos de forma muito mais dispersa.

O associativismo, por exemplo, é um atributo igualmente distribuído por todos os segmentos; a filiação partidária encontra-se presente quase que na mesma proporção em todos os segmentos (em torno de 50\%); o interesse por política, ainda que variável, é alto em todos os segmentos (de $75 \%$ a $100 \%)$ e o engajamento em atividades eleitorais revela um predomínio dos usuários, mas também uma forte presença dos gestores e dos prestadores de serviço. Por fim, em todos os segmentos existe um alto índice (nunca abaixo de 75\%) de competência política subjetiva e uma distribuição bastante desigual da percepção dos segmentos quanto à sua capacidade para influenciar as decisões dentro do conselho, surpreendendo o caso dos gestores, dos quais 50\% afirmaram não ter capacidade alguma de influenciá-las. Os prestadores destacam-se em relação a esse ponto, sendo $75 \%$ os que acreditam ter uma grande capacidade de influenciar as decisões dentro do CMASC.

No que diz respeito aos recursos organizacionais, as entidades do setor não-governamental encontram-se, quase sempre, em situação precária; somente as organizações representativas dos prestadores de serviço têm uma posição mais relevante. As organizações desse segmento são também as que mais freqüentemente buscam apoio político em outras instituições (como os poderes Executivo e Legislativo) e são mais capazes de eleger representantes para cargos públicos estratégicos. No entanto, há uma desigualdade contundente, pois o setor governamental é francamente dominante em relação à sua infra-estrutura organizacional.

Os gestores contam com todos os recursos materiais e financeiros que o Estado põe à sua disposição. Além dos recursos materiais, os representantes dos gestores contam com importantes recursos humanos, que se apresentam sob a forma de apoio dado pelo pessoal técnico - produção de pareceres que embasam as decisões no interior do conselho, pareceres estes que os outros conselheiros têm poucas condições de contestar. Vale lembrar, ainda, um outro aspecto fundamental que muito contribui para entender o predomínio dos gestores, qual seja, a inserção nos conselhos como 
parte de sua atividade profissional. Enquanto nos outros segmentos a "vontade para agir" resulta de um engajamento voluntário (ou, provavelmente, de um longo processo de socialização política) e altamente custoso para a maioria de seus membros, no caso dos gestores à "vontade para agir" é sobreposta à obrigação profissional. ${ }^{7}$ Nesse sentido, os representantes do setor governamental conjugariam de maneira ótima recursos de natureza institucional com uma "disposição para agir" que é fruto de sua própria inserção no aparelho de Estado. Neste caso, enfim, haveria uma clara coincidência entre poder e posição institucional.

Portanto, o papel de destaque que os representantes do governo têm na condução do processo decisório dentro do CMASC pode ser explicado, de forma satisfatória, em termos dos recursos de que cada segmento dispõe. Em especial, a capacidade dos gestores de conduzir esse processo se explica pela sua posição institucional e pelos recursos que essa posição lhe fornece. Tal desigualdade contundente de recursos organizacionais, vale observar, parece ser uma importante variável explicativa para a atuação dominante dos gestores no processo decisório do CMASC, sobretudo se levarmos em consideração que, como vimos acima, os demais recursos estão distribuídos de forma muito menos concentrada.

O mesmo não pode ser dito em relação ao Conselho Municipal de Saúde de Curitiba. Nesse caso, o comportamento de, ao menos, dois dos segmentos que atuam no CMSC - usuários e prestadores de serviço na área de saúde - não se explica de forma satisfatória pelos recursos organizacionais e socioeconômicos.

Os dados não poderiam ser mais persuasivos no sentido de apontar uma clara hierarquia entre os segmentos quanto à posse de recursos. Em primeiro lugar, com destaque, situa-se o gestor. É forçoso reconhecer que, no que se refere às condições individuais e coletivas prévias, o gestor se sobressai enquanto segmento que reúne as condições mais favoráveis para exercer influência política nas reuniões do conselho. Além de dispor de recursos organizacionais ilimitados, ele conta com o monopólio dos dois principais recursos distribuídos no interior do próprio conselho: o de presidir o conselho e o de homologar suas deliberações.

O segmento da sociedade civil que dispõe de maior volume de recursos é o prestador, seguido pelo trabalhador. A fragilidade do usuário em relação à posse de recursos tradicionais, tanto individuais como coletivos, impõe-lhe uma condição de inequívoca inferioridade em relação aos demais segmentos. Quanto aos recursos socioeconômicos de natureza individual, ${ }^{8}$ em especial a renda e a escolaridade, os usuários também estão em franca desvantagem. Além disso, sua inferioridade também pode ser observada em relação às organizações que atuam nos conselhos.

Uma análise superficial dessa situação indicaria que a distribuição da influência política neste conselho deveria seguir a seguinte ordem: gestor, prestador, trabalhador e usuário. Quaisquer que sejam os critérios para definirmos o peso relativo de cada tipo de recurso, essa hierarquia evidencia os limites de uma explicação da influência política baseada exclusivamente na posse de recursos.

Assim como no caso do CMASC, a participação dos gestores no Conselho Municipal de Saúde de Curitiba é, adequadamente, explicada em termos dos recursos de que esse segmento dispõe. A posição intermediária que o trabalhador ocupa em relação à participação efetiva nas reuniões do CMSC também corresponde aos meios de que dispõe em seu favor.

Mais difícil é explicar o "ativismo" dos usuários e, especialmente, a passividade dos prestadores de serviços a partir da posse de recursos. A realidade que nos revela o processo decisório do conselho em seus primeiros dez anos ${ }^{9}$ estaria mais de acordo com o modelo que supõe haver uma simetria entre a participação política e a posse de recursos, caso houvesse uma inversão entre as posições do prestador e do usuário na distribuição de recursos.

Como, então, explicar a influência política do usuário no CMSC? Um dos motivos pelos quais a explicação fundada na posse de recursos convencionais é limitada e, no caso da análise em curso, incapaz de dar conta dos fenômenos investigados deve-se à desconsideração de, ao menos, duas outras dimensões igualmente potencializadoras da ação política: a primeira, mais subjetiva, diz respeito à propensão dos conselheiros para o engajamento político; a segunda refere-se ao padrão de ação política dos grupos. Devemos, portanto, levar em consideração não apenas os 
recursos convencionais, como renda e escolaridade, no caso do indivíduo, ou recursos materiais ou humanos, no caso das organizações. Recursos de natureza menos tangível, mas, nem por isso, menos eficazes, indicando, por exemplo, certa disposição para a participação política, são especialmente relevantes e têm sido levados em consideração em estudos de cultura política (Skocpol e Fiorina, 1999; Schlozman, Verba e Brady, 1999; Fuks, Perissinotto e Ribeiro, 2003).

Para contemplar esses aspectos, levamos em consideração, neste artigo, a presença e o peso de dois tipos de recursos não-convencionais. Primeiramente, os recursos individuais de natureza subjetiva, que indicam, na forma de comportamento - passível de ser medida em termos de engajamento eleitoral, associativismo e filiação partidária - ou de "orientação subjetiva" (competência política), a existência de uma disponibilidade do indivíduo para o ativismo político. Consideramos também recursos coletivos de natureza objetiva, embora menos visíveis do que os recursos financeiros e organizacionais, tais como a rede de apoio político dos grupos organizados que atuam nos conselhos e o padrão de interação política que estabelecem com instituições estatais no encaminhamento de suas demandas.

O pertencimento a associações da sociedade civil e a filiação partidária certamente estão associados à presença de certa motivação para a ação política - além das habilidades políticas específicas adquiridas nessas experiências -, constituindose, portanto, como um importante indicador da presença de condição subjetiva favorável à ação política. Os usuários superam, de longe, os demais segmentos quando se trata da filiação partidária. Apenas 14,3\% dos usuários não são filiados a nenhum partido, em comparação com os $71,4 \%$ dos trabalhadores e com os 50\% dos prestadores e dos gestores. A mesma tendência manifesta-se em relação à preferência partidária. Já a filiação a associações da sociedade civil é bem distribuída entre os segmentos.

A filiação do indivíduo a uma determinada associação ou partido político pode assumir a forma de uma relação passiva ou mesmo puramente formal. Uma maneira de compensar a limitação dessas variáveis quanto à sua capacidade de revelar a intensidade da motivação para agir poli- ticamente é por meio da informação a respeito do envolvimento efetivo dos conselheiros em atividades políticas.

Uma das principais atividades dessa natureza é o engajamento eleitoral. Em relação a esse tipo de atividade político-partidária, chama a atenção a força (ativismo) dos usuários e a fraqueza (apatia) dos prestadores. Em quase todas as atividades eleitorais exercidas durante a campanha para a prefeitura de Curitiba no ano 2.000, a participação do usuário foi superior a 73\%. Já os prestadores não contam com a participação de mais de $25 \%$ de seus representantes nas atividades de campanha eleitoral, exceto na defesa pública do candidato de sua preferência. ${ }^{10}$

Assim como os fatores individuais, devemos também levar em consideração certas condições objetivas que tendem a aumentar a capacidade de ação dos grupos que atuam no conselho. Essas condições estão associadas à presença de recursos coletivos não-convencionais, como a inserção dos grupos em redes de apoio político, das quais participam atores políticos tradicionais, como os partidos políticos, assim como instituições (igreja e universidade, por exemplo) e diversas organizações da sociedade civil. Além disso, as organizações que participam do conselho podem adquirir maior capacidade de ação política mediante vínculos constituídos com atores estatais ou pela experiência acumulada em certas práticas reiteradas, como o recurso ao poder Judiciário e a participação contínua em arenas decisórias, incluindo o próprio conselho.

O tipo de ativismo dominante das organizações que compõem o CMSC varia de acordo com o segmento em questão. Os prestadores de serviço têm uma atuação voltada para o Executivo e o Legislativo. Assim, os representantes dos hospitais de Curitiba (a maioria dos prestadores de serviço) estabelecem contato e encaminham, com freqüência, as suas demandas ao governo municipal e aos vereadores. Já as associações profissionais e os sindicatos de trabalhadores (a maioria dos representantes dos trabalhadores) destacam-se quando se trata de recorrer à esfera judicial. Os usuários, embora também façam uso de outros meios, recorrem, com maior freqüência, a formas não institucionais de ação política, tais como manifestação pública, passeata e abaixo assinado. 
Esse quadro parece indicar que cada segmento ocupa, preferencialmente, certos nichos de ação política, possivelmente aqueles espaços mais adequados aos recursos organizacionais de que dispõe. Além disso, as organizações tendem a canalizar sua ação para aqueles atores estratégicos que fazem parte de sua rede de apoio político ou para aqueles espaços institucionais mais permeáveis às suas demandas. Isso pode ser verificado em termos do tipo de apoio predominante recebido por cada segmento. Portanto, os segmentos contam com maior apoio exatamente daqueles grupos e instituições a quem dirigem, preferencialmente, a sua ação política.

Assim, os prestadores afirmam contar mais com o apoio do Legislativo e do Executivo. Por outro lado, esse segmento indica, com pouquíssima freqüência, ter o apoio de organizações da sociedade civil. Obviamente, as organizações da sociedade civil constituem uma importante rede de apoio político para os usuários. Estes identificaram as instituiçôes religiosas, os sindicatos e as universidades como os seus principais aliados na sociedade. Os trabalhadores contam com um apoio ainda mais concentrado nas organizações da sociedade civil.

Esse conjunto de condições, incluindo tanto aquelas de ordem individual e de caráter subjetivo como as que se referem às organizações e assumem uma qualidade objetiva, revela os limites de uma explicação fundamentada na posse de recursos convencionais. Assim, a militância partidária, que se reflete no engajamento eleitoral, indica que a motivação para ação política pode estar compensando a fragilidade dos usuários em relação a outros recursos (organizacionais, de renda e de escolaridade). O apoio recebido por organizações da sociedade civil e a prática associativa (especialmente, a de bairro) também parecem compensar, em parte, a menor freqüencia com que esse segmento atua junto às instituições políticas.

Por último, mas não menos importante, devemos considerar o peso da representação de cada segmento no conselho como um dos fatores que exercem influência sobre seu comportamento político. Nesse caso, o usuário leva uma grande vantagem, pois o CMSC, sendo paritário, é constituído por dezesseis representantes dos usuários e dezesseis representantes dos demais segmentos. ${ }^{11}$
Mais difícil é explicar a situação do prestador. Sua inércia não é congruente com a abundância de recursos de que dispõe. Conforme veremos a seguir, nesse caso, o fato de o prestador reunir condições favoráveis para a ação política não se traduz em uma ação efetiva. Isso significa que a posse de um determinado tipo de recurso não implica a sua conversão em influência política. O conceito central aqui é o de "disponibilidade", ou seja, se alguém dispõe de algum recurso significa que ele pode, se assim o desejar, fazer uso desse recurso. Podemos, nesse caso, supor que não haja interesse por parte dos prestadores em fazer uso de seus recursos.

Sustentamos, nessa seção, o argumento de que uma explicação da influência política basea$\mathrm{da}$, exclusivamente, na posse de recursos convencionais é limitada. Em nosso estudo, a evidência mais incisiva dessa limitação é o fato de que a distribuição semelhante de recursos nos dois conselhos (CMASC e CMSC) entre os diversos segmentos não resulta na semelhança do comportamento político de, ao menos, dois dos segmentos (usuários e prestadores de serviço). O ativismo dos usuários e a passividade dos prestadores de serviço no interior do CMSC não podem ser explicados de forma tão direta pelos recursos organizacionais e socioeconômicos que eles possuem.

\section{Contexto e estrutura}

Até o momento, tentamos explicar a participação e a influência política dos conselheiros a partir de duas perspectivas: 1) centrada na atuação dos conselheiros no processo decisório, tal como recomenda a abordagem decisional; 2) preocupada com as condições prévias à ação dos conselheiros, com ênfase na posse de recursos, conforme indicação da abordagem posicional. Inovamos apenas ao incluir um elenco de recursos não-convencionais individuais - associados a formas de engajamento político - e coletivos - em especial, a rede de apoio político e os padrões de ação política.

No caso do Conselho Municipal de Saúde, a segunda perspectiva ofereceu uma explicação plausível para a participação dos gestores e dos trabalhadores. Notadamente, no caso do gestor, 
pode-se dizer que a sua preponderância no processo decisório corresponde aos amplos recursos de que esse segmento dispõe. No caso do usuário, o modelo baseado na posse de recursos revela-se limitado, embora seja possível argumentar que uma versão ampliada deste possa identificar o engajamento eleitoral, a filiação partidária e o associativismo - responsáveis pela criação de condições subjetivas favoráveis à ação política como recursos não-convencionais, compensando a pouca disponibilidade de recursos tradicionais $\mathrm{e}$ criando, portanto, um contexto propício para a sua participação substantiva e influência nas reuniões do conselho.

No entanto, conforme já observado, a posse de recursos não é capaz de fornecer uma explicação adequada para a participação política dos prestadores de serviço no CMSC. O que o modelo fundado na posse de recursos deixa de considerar é que a mera posse de recursos não se traduz, automaticamente, em participação política. Em relação a esse aspecto, a abordagem decisional é esclarecedora: somente o estudo de processos decisórios concretos pode revelar se e em que medida os recursos de que dispõem os diversos atores envolvidos são convertidos em influência política.

Possivelmente, no caso dos prestadores, o principal motivo desta discrepância entre recursos e ação política é a falta de interesse em participar ativamente no processo decisório. Além da posse de recursos, há de se levar em consideração quais são os espaços públicos que um determinado ator elege como arenas privilegiadas de ação política. Certamente, o usuário entende ser o CMSC um espaço central de ação política, especialmente considerando a escassez de canais institucionais abertos à participação política desse segmento. O gestor, por obrigação e por interesse, tem que atuar e, mesmo, conduzir o conselho, uma vez que: 1) ele é uma instância estatal aberta à participação da sociedade civil; 2) o conselho é um espaço estratégico para o governo consolidar e ampliar sua base de apoio na sociedade civil, tanto no sentido mais amplo da busca de legitimidade como no sentido mais específico do apoio político e eleitoral; 3) se ele não levar a sério a atuação no conselho, sua dinâmica e suas deliberações podem fugir de seu controle e, portanto, envolver custos políticos.
No caso do prestador, parece prevalecer o entendimento de que, ao contrário do que ocorre no Conselho de Assistência Social e no Conselho da Criança e do Adolescente, o CMSC não delibera, com freqüência, sobre assuntos de seu interesse. Podemos supor, então, que o prestador perceba como altos os custos da ação, ${ }^{12}$ tendo em vista a expectativa de um baixo "retorno". Além disso, parece prevalecer entre os prestadores que atuam no CMSC o entendimento de que este conselho não se constitui como uma arena relevante de tomada de decisão política na área de saúde. Essa questão é central e está associada, de um lado, às competências do conselho ${ }^{13} \mathrm{e}$, de outro, às modalidades e aos conteúdos de suas deliberações.

Não podemos, portanto, estudar a influência política no interior de uma determinada instituição pública sem levar em conta o contexto em que ela se insere, incluindo, nesse caso, a seu peso no sistema mais amplo de arenas públicas (Hilgartner e Bosk, 1988), assim como a percepção dos diversos atores envolvidos a respeito da relevância desta instituição. Nesse sentido, a quantidade e mesmo a qualidade da participação numa arena específica nem sempre é um bom indicador da influência política real dos atores.

Porém, não é apenas o contexto institucional que conta. Sem levarmos em consideração o contexto histórico da arena, não estaremos em condição de avaliar o peso da participação de cada ator envolvido, assim como o padrão de interação entre os grupos. O legado constituído pelas lutas e alianças, a história prévia da área em questão, a forma pela qual o conselho foi instituído (por exemplo, como fruto de uma longa mobilização de forças sociais ou a partir da iniciativa do Estado), tudo isso define o "perfil" do conselho, condicionando, de alguma forma, a influência dos grupos nessa arena.

Além disso, diversas variáveis locais (índice de associativismo, orientação ideológica do governo local, força dos partidos e dos sindicatos de esquerda, desenvolvimento socioeconômico da comunidade, cultura política predominante) forçosamente afetam não só o desempenho como também o padrão de interação no interior desse tipo de instituição. Assim, apesar da proliferação de instituições do mesmo tipo por todo o Brasil, em função dos incentivos institucionais e financeiros 
existentes a partir de 1988 (Arretche, 1999), os conselhos municipais assumem formas distintas em função da realidade local em que operam (Cortês, 1998).

Entre essas variáveis, uma é especialmente relevante no caso do CMASC - seu processo de gestação e consolidação. Basta observar que este processo contou, no seu início, com a atuação efetiva de várias forças ligadas aos movimentos populares e com instituições ligadas à esquerda. A reação do governo local, à época capitaneado por Rafael Greca de Macedo (PDT), foi rápida e contundente, visando a evitar qualquer influência significativa dos grupos de esquerda no interior do Conselho. A conduta do governo pautou-se por tentar se aliar aos representantes dos usuários, segmento composto majoritariamente por associações de bairro, e aos prestadores de serviço, formados por entidades filantrópicas, sempre com vistas a isolar o segmento dos trabalhadores do setor, inicialmente composto por entidades críticas ao governo (Central Única dos Trabalhadores e Conselho Regional de Serviço Social).

A primeira gestão do CMASC ainda contou com uma distribuição igualitária da representação entre o setor não-governamental: três representantes dos usuários, três dos prestadores e três dos trabalhadores. No entanto, a pressão governamental contra as entidades críticas ao governo levou a uma reforma do regimento que promoveu uma redução da representação dos trabalhadores, agora composto apenas por um único membro, e o aumento, para quatro, da representação dos usuários e dos prestadores de serviço. As seguidas derrotas e o controle ostensivo do setor governamental sobre o Conselho desestimularam as entidades de esquerda, levando-as a desistir de participar do conselho e consolidando, assim, o controle oficial sobre a instituição.

Em segundo lugar, também como expressão dos esforços do governo e de seus aliados para controlar o CMASC, vale lembrar a conferência, momento em que os representantes não-governamentais são escolhidos. Segundo nossas observações, o processo de escolha dos representantes não-governamentais foi amplamente controlado pelo governo e seus aliados, consolidando-se, assim, um procedimento que se iniciara desde os primeiros momentos de criação dessa instituição.
As forças críticas e oposicionistas foram afastadas do processo de eleição dos representantes nãogovernamentais desde as primeiras conferências, sendo que na Conferência observada por nós nenhuma chapa concorrente foi apresentada. O controle sobre esse processo garantiu que somente representantes alinhados com a visão governamental fossem conduzidos ao conselho, o que garantiu, por fim, um processo decisório profundamente harmonioso. Não há contestação no interior do CMASC porque todas as forças que poderiam contestar a orientação ali predominante foram excluídas em momentos anteriores ao processo decisório.

A esse respeito, é interessante observar que, diferentemente da tradição pluralista, para a qual a apatia de alguns grupos revelaria certa satisfação com a própria condição, outros autores apontam para a possibilidade de se interpretar tal passividade (ou abstenção) política como algo produzido por relações de poder regulares, as quais, por meio da produção de derrotas permanentes, incutiriam nos dominados a sensação de que não haveria nada a fazer para mudar a situação em que se encontravam. Criar-se-ia, assim, uma adaptação psicológica que produziria um sentimento de estar desprovido de poder (sense of powerlessness), cuja perpetuação poderia levar os membros do grupo à autodepreciação e ao fatalismo, gerando abstenção em vez de resistência (Gaventa, 1980, pp. 16-18). Ainda que a situação do CMASC não tenha chegado a esses extremos (em parte, devido ao curto período de tempo da experiência em questão), o fato é que os representantes das forças oposicionistas dentro do Conselho anteciparam que seriam, como ocorrera até então, sistematicamente derrotados pelo governo e, por isso, optaram por se retirar dessa arena decisória. Enfim, ainda que a situação vivida nesse conselho não tenha produzido "passividade", já que se trata de grupos e instituições profundamente engajados na luta social e política, a ação governamental conseguiu fazer como que eles desistissem de atuar dentro do CMSAC.

Um outro fator que poderia contribuir para entender o processo de exclusão produzido pelo funcionamento dessa instituição é o fato de alguns representantes dos prestadores de serviço afirmarem insistentemente não ser papel do CMASC dis- 
cutir "política". Nesta visão de mundo, a "caridade" é uma virtude e a política (sempre entendida como política partidária interessada), um defeito. Esse tipo de visão seria "funcional" para as intenções do governo de barrar a participação de forças oposicionistas (elementos ligados a CUT, ao Partido dos Trabalhadores e ao CRESS), estigmatizadas como portadoras de "interesses políticos" que não combinam com o espírito caritativo da assistência social. A caridade seria, assim, uma espécie de "mito" sistematicamente mobilizado pelos grupos dominantes com vistas a desqualificar e excluir grupos que tenham alguma pretensão a fazer-lhes oposição, consolidando, dessa forma, um "viés" das instituições em questão no momento de pensar a política de assistência social.

\section{Conclusão}

Esse artigo tratou da questão da participação política em termos da capacidade dos atores de influenciar o processo decisório. Inicialmente, avaliamos a possibilidade de que o real exercício da influência política seja definido em termos do resultado concreto do conflito político, indicado pelo sucesso de determinados atores no processo decisório, independentemente da posição institucional e, em conseqüência, dos recursos de que dispõem. A abordagem decisional revelou-se limitada para explicar a influência política no interior dos conselhos estudados quando percebemos, por meio de alguns indícios, que a conduta dos atores no processo decisório e os resultados ali produzidos poderiam estar sendo condicionados por fatores exteriores a esse processo.

Em seguida, consideramos a hipótese de que a posse de determinados recursos explicaria a distribuição da participação política nos conselhos gestores de políticas públicas em Curitiba. Nossas conclusões indicaram que os recursos são condições necessárias, mas não suficientes para que haja participação e o exercício efetivo da influência política, já que os atores com menos recursos tinham uma atuação mais intensa e eficaz dentro dos conselhos do que outros que possuíam uma quantidade maior de recursos de diversas naturezas.

Por fim, levamos em consideração os fatores que configuram os contextos (interno e externo), nos quais os conselhos se inserem, e "estruturaram", em alguma medida, os distintos padrões de ação e interação no interior dessas instituições. A introdução desses fatores na análise permitiu, a nosso ver, superar as limitações das abordagens que levam em conta apenas interações observáveis no processo decisório ou os recursos possuídos pelos atores políticos. Desse ponto de vista, pensar a influência política exclusivamente em termos de recursos ou de interferência direta no processo decisório seria reduzir a explicação de tal fenômeno a um formalismo incapaz de dar conta das circunstâncias reais em que as arenas se estruturam e o processo decisório se desdobra.

Nesse sentido, pensamos que a análise do contexto (interno e externo) como elemento que afeta a conduta política dos atores dentro dos conselhos deve levar em consideração cinco fatores: 1) existência de arenas alternativas; 2) interferência do governo na eleição dos representantes não-governamentais; 3) existência de valores e ethos específicos de cada policy domain; 4) natureza da relação entre governo e sociedade civil na comunidade em análise, relação esta que sofre influência de inúmeros fatores, tais como o grau de associativismo existente na sociedade e a orientação ideológica do poder Executivo; e, por fim, 5) contexto interno dos conselhos, isto é, seu desenho institucional, definido, em grande parte, pela história de sua institucionalização e pela trajetória das forças sociais que nele atuaram.

Afirmamos no início deste artigo que nosso objetivo não era defender uma relação de exclusão, mas de complementaridade, entre as diferentes abordagens sobre o poder. Uma análise das relações de poder em instituições de participação ampliada deve, portanto, a nosso ver, levar em consideração tanto as dimensões estruturais, que modelam as capacidades e as preferências dos atores, como as interações concretas entre eles, as quais, por seu caráter acentuadamente estratégico, trazem consigo sempre resultados que não podem ser simplesmente derivados dos aspectos estruturais que constrangem a ação.

As conseqüências dessa postura analítica para a teoria democrática são bastante relevantes. Seguindo-as, podemos perceber que a ampliação da participação política - objetivo universal de qualquer teoria democrática mais ousada - não 
comporta soluções puramente institucionais, como parece sugerir, por exemplo, Hannah Arendt. Não basta que instituições participativas estejam à disposição para que a ampliação da participação ocorra. Os constrangimentos socioeconômicos, simbólicos e políticos podem funcionar como um poderoso obstáculo à participação ou até mesmo aprofundar a desigualdade política. Por outro lado, é verdade que a simples existência dessas instituições, ela própria o resultado da luta política, permitiu a incorporação de determinados atores políticos no processo de tomada de decisão pública, antes monopolizado pela burocracia estatal, incorporação esta que pode produzir efeitos não antecipados por uma análise puramente estrutural.

\section{BIBLIOGRAFIA}

ARRETCHE, M. (1999), "Políticas sociais no Brasil: descentralização em um Estado federativo". Revista Brasileira de Ciências Sociais, 40 (14): 111-141.

BACHRACH, Peter \& BARATZ, Morton S. (1969a), "Two faces of power", in R. Bell, D. V. Edwards e H. R. Wagner, Political power: a reader in theory and research, Nova York, The Free Press.

.(1969b),"Decisions and non-decisions: an analytical framework", in R. Bell, D. V. Edwards e H. R. Wagner, Political power: a reader in theory and research, Nova York, The Free Press.

BOURDIEU, Pierre. (1989), "Espaço social e gênese das "classes", in O poder simbólico, Lisboa, Difel.

COBB, Roger \& ROSS, Marc Howard. (1997), Cultural strategies of agenda denial: avoidance, attack, and redefinition, Lawrence, University of Kansas Press.

CÔRTES, S. M. V. (1998), "Conselhos municipais de saúde: a possibilidade dos usuários participarem e os determinantes da participação". Ciência e Saúde Coletiva, III (1): 6-17.
CRENSON, Mathew A. (1971), The um-politics of air pollution: a study of non-decisonmaking in the cities. Baltimore/Londres, The Johns Hopkins Press.

DAHL, Robert. (1970), "Uma crítica do modelo de elite dirigente", in política II, Rio de Janeiro, Zahar. Sociologia . (1989), Who governs?. New Haven, Yale University Press.

FOUCAULT, Michel.(1995), "O sujeito e o poder", in P. Rabinow e H. Dreyfus, Michel Foucault: uma trajetória filosófica (para além do estruturalismo e da hermenêutica), Rio de Janeiro, Forense Universitária.

FUKS, Mario. (2002), "Participação política em conselhos gestores de políticas sociais no Paraná, in R. M. Perissinotto e M. Fuks (orgs.), Democracia: teoria e prática. Rio de Janeiro, Relume Dumará, pp. 245-272.

. (2004), "Democracia e participação no Conselho Municipal de Saúde de Curitiba”, in M. Fuks, R. M. Perissinotto e N. R. de Souza (orgs.), Democracia e participação: os conselhos gestores do Paraná. Curitiba, Editora da UFPR, pp. 13-44.

FUKS, Mario; PERISSINOTO, Renato \& RIBEIRO, Ednaldo Aparecido. (2003), "Cultura política e desigualdade: o caso dos conselhos municipais de Curitiba". Revista de Sociologia e Política, 21: 125-145.

GAVENTA, John. (1980), Power and powerlessness: quiescence and rebellion in an Appalachian Valley. Chicago, University of Illinois Press.

HILGARTNER, Stephen \& BOSK, Charles L. (1988), "The rise and fall of social problems: a public arenas model". American Journal of Sociology, 94 (1): 53-78.

KAPLAN, A. \& LASSWELL, H. (1998), Poder $e$ sociedade. Brasília, Editora da UnB.

LUKES, Steven. (1976), Power: a radical view. Londres, The MacMillan Press. 
MELO, M. A. (2002), Reformas constitucionais no Brasil: instituições políticas e processo decisório. Rio de Janeiro, Revan.

PERISSINOTTO, R. M. (2002), "Democracia e participação: o caso do Conselho Municipal de Assistência Social de Curitiba", in R. M. Perissinotto; M. Fuks (orgs.), Democracia: teoria e prática. Rio de Janeiro, Relume Dumará, pp. 211-244.

PERISSINOTO, Renato; FUKS, Mario; SOUZA, Nelson Rosário de. (2003), "Participação e processo decisório em alguns conselhos gestores de Curitiba". Revista Paranaense de Desenvolvimento Ipardes, 105: 75-100.

POLSBY, N. (1963), Community power and political theory. New Haven, Yale University Press.

SCHLOZMAN, K., VERBA, S. \& BRADY, H. (1999), "Civic participation and the equality problem", in T. Skocpol e M. Fiorina (orgs.), Civic engagement in American democracy, Washington D.C., The Brookings Institution Press.

SKOCPOL, T \& FIORINA, M. (1999), "Making sense of the civic engagement debate", in T. Skocpol e M. Fiorina (orgs.), Civic engagement in American democracy, Washington D.C., The Brookings Institution Press.

WRIGHT MILLS, C. (1985), "A elite do poder: militar, econômica e política", in $\mathrm{H}$. Fernandes (org.), Wright Mills, São Paulo, Ática (col. Grandes Cientistas Sociais, 48).

\section{Notas}

1 Os seguintes conselhos municipais de Curitiba foram investigados: Conselho Municipal de Saúde de Curitiba (CMSC), Conselho Municipal de Assistência Social de Curitiba (CMASC), Conselho Municipal dos Direitos da Criança e Adolescente de Curitiba (Comtiba), Conselho Municipal do Emprego e Relações de Trabalho de Curitiba
(CMERT). Nossa análise focalizará, prioritariamente, o CMSC e o CMASC. Ambos são compostos por quatro segmentos: gestores (representantes do governo), trabalhadores, prestadores de serviço e usuários do setor em que o conselho atua. Há diferença, porém, no que diz respeito ao peso de cada um desses segmentos. O Comtiba é formado apenas por dois segmentos - governamental e nãogovernamental -, sendo este último formado apenas por prestadores de serviço. Já o CMERT é um conselho tripartite, constituído por sindicatos patronais, sindicatos dos trabalhadores e por representantes do governo municipal. No caso do CMERT, o estudo limitou-se à aplicação de questionários, ao passo que nos demais também foram coletadas informações nas atas das reuniões dos conselhos.

2 Os dados foram coletados em pesquisa financiada pelo CNPq, coordenada pelo professor Mario Fuks e desenvolvida pelo núcleo de pesquisa "Democracia e Instituições Políticas Paranaenses". A pesquisa também contou com a consultoria na área de estatística e processamento de dados do professor Malco Camargos, da PUC-MG.

3 Considerando que o presente texto tem como foco questões teóricas e metodológicas relativas ao conceito de poder/influência, não faremos uma apresentação sistemática dos dados e da especificidade de cada conselho investigado. Para tanto, sugerimos a leitura de Fuks, Perissinotto e Souza (2003, 2004); Fuks, Perissinotto e Ribeiro (2003); Fuks (2002); Perissinoto (2002). Ver também o banco de dados em Fuks e Perissinotto, Banco de dados, estudo dos conselhos municipais de Curitiba (2002), no site http://www.nadd.prp.usp.br/cis/index.aspx.

4 O conselho é composto por 32 membros, distribuídos da seguinte forma: usuários (16), trabalhadores de saúde (8), prestadores (4) e gestores (4).

5 A presença de "contestação" foi registrada sempre quando a intervenção do segundo ator se opôs explicitamente à do que iniciou o debate.

6 Os dados referentes aos recursos foram coletados mediante entrevista com trinta conselheiros que participaram da gestão de 1999-2001 do Conselho Municipal de Saúde de Curitiba. Do conjunto de conselheiros dessa gestão, apenas dois conselheiros não foram localizados e, portanto, não foram entrevistados. A distribuição das entrevistas por 
segmento foi a seguinte: quinze usuários, sete trabalhadores, quatro prestadores de serviço e quatro gestores. A predominância do segmento "usuário" explica-se pelo fato de os conselhos de saúde serem "paritários", sendo 50\% de seus membros usuários do sistema de saúde. No caso do CMASC, foram feitas entrevistas com dezessete conselheiros durante a gestão de 1999-2001. Desse total, oito eram gestores, quatro usuários, quatro prestadores de serviço e um trabalhador.

7 Isso talvez explique o baixo índice de "competência política subjetiva" no que diz respeito ao processo decisório dentro do conselho por parte dos gestores. Tomados individualmente, de fato, não são eles capazes de conduzir o processo decisório no CMASC, mas sim o governo como instituição.

8 Em nossa pesquisa, os agentes no interior dos conselhos são identificados como portadores de dois tipos de recursos: 1) "recursos individuais", que apresentam uma dimensão objetiva (perfil socioeconômico e educacional dos conselheiros) e uma dimensão subjetiva (motivações para a ação política); e 2) "recursos coletivos", que se referem aos recursos organizacionais (financeiros, materiais e humanos), políticos e de "rede", pertencentes às entidades representadas no CMSC.

9 Importante observar que os dados de que dispomos em relação aos recursos, no CMSC, cobrem apenas uma gestão do conselho (1999-2001). Supomos, então, uma relativa estabilidade, ao longo do tempo, em termos dos recursos de que cada segmento dispõe.

10 Há uma relação direta entre o comportamento político dos conselheiros - expresso na forma de filiação partidária, associativa e engajamento eleitoral e suas orientações subjetivas, em especial no que se refere à confiança do indivíduo em relação à sua capacidade de influenciar a política. Assim, os usuários são os que, com maior freqüência, se percebem como influentes no campo da política $(86,7 \%)$. Os gestores (75\%) e os trabalhadores $(71,4 \%)$ também expressam um alto grau de competência subjetiva, ao contrário do segmento prestador (25\%), no qual prevalece a percepção de uma baixa competência política. Portanto, é exatamente aquele segmento da sociedade civil cujo comportamento político é mais ativo que também se considera mais capaz de influenciar a política.
11 Sendo oito trabalhadores, quatro gestores e quatro prestadores de serviço.

12 Devemos também pensar na possibilidade de que, no CMSC, a influência dos prestadores ocorra de acordo com a "regra das reações antecipadas". O fato de esse segmento não "agir" pode ser explicado, parcialmente e em determinadas circunstâncias, pelo seu lugar estratégico na política em questão, o que força os decisores a levar em consideração seus interesses, mesmo que eles demonstrem passividade no processo decisório.

13 Atuando prioritariamente como instância de fiscalização, o conselho estimula mais a ação dos prestadores no sentido reativo do que propriamente ativo. Isso porque, nesse caso, os prestadores podem estar mais interessados em atuar no sentido de criar obstáculos às ações do conselho que, eventualmente, podem prejudicar membros do setor do que participar do conselho para encaminhar propostas que atendam seus interesses. 


\section{RECURSOS, DECISÃO E PODER: CONSELHOS GESTO- RES DE POLÍTICAS PÚBLICAS DE CURITIBA}

Mario Fuks
Renato Perissinotto

Palavras-chave: Participação política; Influência política; Conselhos gestores.

Este artigo investiga a influência política em instituições de participação ampliada. Tendo como referencial empírico os conselhos gestores de políticas sociais em Curitiba, são abordadas questões teóricas e metodológicas relativas ao conceito de poder/influência, buscando identificar o modelo analítico mais apropriado para o estudo da influência política no interior de instituições desta natureza. Após considerar duas das principais abordagens (decisional e posicional) usualmente utilizadas no estudo do exercício do poder político, conclui-se que cada uma delas, por si só, é incapaz de explicar a distribuição da influência política no interior dos conselhos. Os autores sugerem a elaboração de um modelo capaz de integrar as virtudes de cada uma das perspectivas e, ao mesmo tempo, incorporar variáveis de natureza contextual.

\section{RESOURCES, DECISION, AND POWER: PUBLIC POLICIES MANAGEMENT COUNCILS IN CURITIBA}

Mario Fuks

Renato Perissinotto

Keywords: Political participation; Political influence; Management councils.

This article investigates the political influence in institutions of enlarged participation. Having as empirical referential the social policies management councils in Curitiba, both theoretical and methodological issues are approached in relation to the concept of power/influence, seeking to identify the most appropriate analytical model for studying the political influence within such institutions. After having considered two of the main approaches (decisional and positional) commonly used in studying the practice of political power, we have concluded that each one alone proves to be unable to explain the distribution of political influence within the councils. The authors suggest the elaboration of a model capable of integrating the virtues of each one of the perspectives and, at the same time, incorporating variables of contextual nature.

\section{RESSOURCES, DÉCISION ET POUVOIR: LES CONSEILS DE GESTION DE POLITIQUES PUBLIQUES À CURITIBA}

Mario Fuks
Renato Perissinotto

Mots-clés: Participation politique; influence politique; Conseils de gestion.

Cet article enquête à propos de l'influence politique dans les institutions où il existe une participation sociale plus développée. Ayant comme référence empirique les conseils de gestion de politiques publiques à Curitiba, nous abordons des questions théoriques et méthodologiques relatives au concept de pouvoir et d'influence. Nous cherchons à identifier le modèle analytique le plus approprié pour l'étude de l'influence politique à l'intérieur d'institutions de cette nature. Après avoir considéré deux des principaux abordages (décisionnel et structurel) normalement employés dans l'étude de l'exercice du pouvoir politique, nous concluons que chacune d'elles est, individuellement, incapable d'expliquer la distribution de l'influence politique à l'intérieur des conseils. Nous suggérons l'élaboration d'un modèle capable d'intégrer les vertus de chacune des perspectives et, en même temps, d'incorporer des variables de nature contextuelle. 